\title{
Project design of a device for express analysis for Coronaviridae antigens based on Omron industrial programmable logic controller
}

\author{
S.N. Kostarev ${ }^{1,2}$, O.V. Kochetova ${ }^{3}$, N.A. Tatarnikova ${ }^{2}$, T.G. Sereda ${ }^{2}$ \\ ${ }^{1}$ Perm National Research Polytechnic University \\ ${ }^{2}$ Perm State Agrarian-Technological University named after academician D N Prianishnikov \\ ${ }^{3}$ Perm Institute of the FPS of Russia \\ RUSSIA
}

\begin{abstract}
Coronaviruses take the lead in gastrointestinal pathologies of animals and are spread all around the world. Causative agents of coronaviruses belong to Nidovirales order, Coronaviridae family which includes 2 subfamilies: Toroviridna (genera Torovirus and Bafinivirus) and Coronaviridna (genera Alphavirus, Betavirus, Gammavirus). Dividing of the latter by genera (groups I-III) was based on serological cross-reactions. Group I includes pathogens causing diseases in animals, such as swine coronavirus, feline infectious peritonitis virus. Group II includes pathogens of veterinary importance, such as $\mathrm{BCoV}$, porcine hemagglutinating encephalomyelitis virus, horse coronavirus, viruses infecting mice and rats, as well as human coronaviruses that cause respiratory damage. Group III includes at the moment only avian coronaviruses. Coronavirus got its name in 1968 because of its special structure and appearance - it has spikes which resemble solar corona. In humans, coronavirus was first isolated by $D$. Tyrrell and M. Bynoe in 1965 from a patient with acute respiratory disease. Severe acute respiratory syndrome (SARS) in 2002, and then Middle East respiratory syndrome (MERS) in 2012 made specialists significantly increase the level of epidemic danger of coronaviruses. Due to its high virulence, virus multiplication rate in macrophages, pathogen replication, and antibody production increase significantly. At the end of 2019, coronavirus strain 2019-nCoV of Betacoronavirus genus was found in patients with pneumonia in China, and by early 2020 it spread all around the world. In animals, coronavirus leads to damage to mucous membranes. The amount of economic damage associated with disease caused by coronavirus is significant and includes death of animals, decreased meat and dairy productivity, decreased weight gain, culling, loss from abortion and infertility. In this regard, a demand arose for developing project of a device for express analysis for Coronaviridae antigen for the early
\end{abstract}

diagnosis of coronaviruses. Based on the express analysis technique using solid-phase immunochromatographic medium, a project for express analysis for Coronaviridae antigen based on Omron industrial programmable logic controller was developed; it includes process chart for equipment, functional diagram and logical equations.

Keywords - CoV, Coronaviridae antigens, Omron, Ladder Diagramm.

\section{INTRODUCTION}

$\mathrm{V}_{\mathrm{i}}$ iral infections account for $60 \%$ of all known infectious diseases of humans, animals and plants. Viral infections are one of the leading causes of death in humans and animals. Epizootology of coronavirus infections is characterized by their ability to spread rapidly and widely [1-3]. They often spread over entire countries and even continents. A number of devastating outbreaks of cattle plague and foot-andmouth disease are known that led to the mass death of animals. Another important feature of viral infections is significant ability of their pathogens to adapt and change biological properties under the influence of environmental conditions $[4,5]$. This factor can result in the development of new variants of the pathogen that can significantly differ in their antigenic composition and virulence. In this regard, the range of objects affected by the virus can also change [6-8]. Many viral infections of animals are anthropozoonotic, i.e. can spread to humans. Emergence and development of viral epizootics is possible only in the presence of an epizootic chain and depends on the features of its links - biological properties of pathogen, its transmission methods, and the degree of organism resistance. It should be mentioned that when passing through an organism, viruses increase their virulence, so, they cause disease in an increasing number of individuals $[9,10]$.

Currently, diagnostics of disease and treatment is performed without automated equipment, so, it is accompanied by the risk of infection transmission to medical personnel and also delays the time of diagnostics and treatment. 


\section{MATERIALS AND METHODS}

Theoretical approaches to the design of a device for express analysis were based on the theory of virology, applied finite state machine theory and simulation. Practical design was performed using Omron controller software and hardware that was well-established in medical industry. COVID-19 respiratory disease testing is possible with two main methods: molecular recognition and serological testing. Today, for the diagnosis of SARS-CoV-2 methods are used [11]:

- identification of viral nucleic acid (RNA);

- detection of viral antigen (proteins);

- detection of antibodies against the virus that occur in the body.

It was proposed to use a set of diagnostic probes as indicators of coronavirus antigen which are nitrocellulose membrane containing monoclonal $\mathrm{CoV}$ antibodies. $\mathrm{CoV}$ antigen detection takes place in a solid phase immunochromatographic state. The rapid diagnostic test (TED) DNK-1419-1, developed by the Chinese company Dynamiker [12] , allows to determine the presence of IgG and $\operatorname{IgM}$ antibodies in a patient with $92 \%$ accuracy and is used in China. It uses a method based on the activity of cleavage of collateral single-stranded DNA (ssDNA).

Construction of device model and simulation of program was performed using CX-One Software.

\section{RESULTS OF A SOLUTION FOR DESIGNING A DEVICE FOR EXPRESS ANALYSIS}

\subsection{The study of the relevance of the design of the device}

The coronavirus family includes four groups: $\alpha, \beta, \gamma$ and $\delta$, affecting humans and various animals (see table 2). Currently, the SARS-CoV-2 coronavirus (CoVID19) is particularly dangerous, affecting almost all countries. On May 1, 2020, 3274747 infections were confirmed, 1023911 people recovered and 233792 people died. Currently, there is an increase in diseases, in Fig. 1 shows the dynamics of confirmed diseases in the world for the period 01.04.20 to 05.01.20.

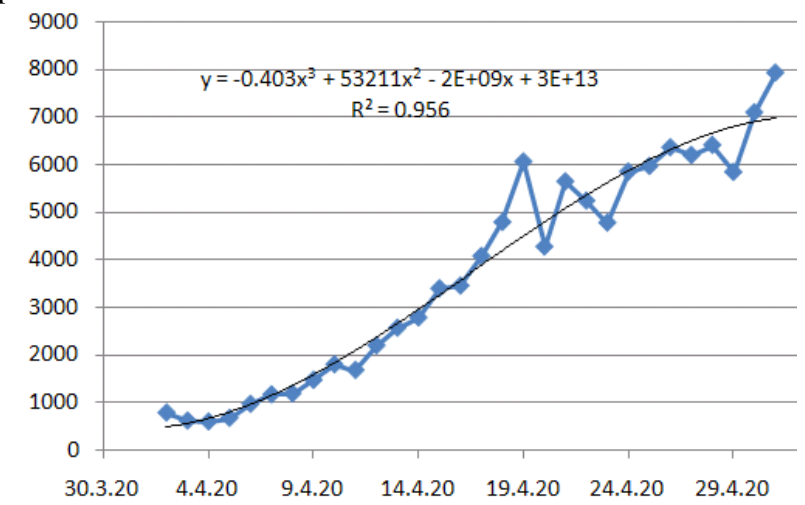

Fig. 1. The dynamics of confirmed diseases in the world for the period 01.04.20 to 05.01.20 is shown

The increase in diseases can be explained by several reasons: insufficient self-isolation of people, lack of the required number of available express analyzers, and a number of other factors [13-14].

\subsection{Studying the preliminary symptoms of disease}

To make a device for the rapid diagnosis of disease and infection with $\mathrm{CoV}$ coronaviruses family, it was necessary to define symptoms of disease with a diagnosis specification. Primary signs of the disease are usually fever and respiratory tract irritation; they require subsequent diagnosis of disease [15-18]. Causative agent is transmitted by aerosol, fecal-oral and contact route. Coronaviruses, as a rule, cause damage to respiratory and gastrointestinal tract. The generalized clinical sequence of the external manifestation of coronavirus consists of several stages (table 1) [19-22]. The incubation period lasts on average 12-14 days, and in some cases reaches 21 days. This period in our model we took for zero. At the first stage of the development of the disease (the onset of the disease), a slight increase in body temperature to $37.5-37.6{ }^{\circ} \mathrm{C}$, headache, runny nose, weakness, conjunctivitis, and increased fatigue are noted. In the second stage of the disease, the body temperature rises to $38-39{ }^{\circ} \mathrm{C}$, a sore throat appears, a complete loss of smell. In the third - (less common signs of the disease) such as blue fingers, the appearance of reddish spots on the skin of the hands and other departments. The fourth stage (respiratory) is characterized by a dry, painful cough, shortness of breath, a person has a feeling of lack of air. Rarely, the disease goes into the fifth stage, when damage to the organs of the gastrointestinal tract occurs, manifested by nausea, vomiting, diarrhea.

Table 1. Stages of the sequence of coronavirus clinical signs

\begin{tabular}{|c|c|c|}
\hline Stage & Period & Symptom of disease \\
\hline 0 & $\begin{array}{l}\text { Incubation period, } \\
14-21 \text { day }\end{array}$ & No manifestation \\
\hline 1 & $\begin{array}{l}\text { Disease onset, first } \\
\text { clinical signs }\end{array}$ & $\begin{array}{l}\text { Fever up to } 37.5-37.6^{\circ} \\
\mathrm{C} \text {, headache, } \\
\text { runny nose, weakness, } \\
\text { conjunctivitis, increased } \\
\text { fatigue }\end{array}$ \\
\hline 2 & $\begin{array}{l}\text { Development of } \\
\text { clinical signs }\end{array}$ & $\begin{array}{l}\text { Body temperature rises } \\
\text { to } 38-39{ }^{0} \mathrm{C} \text {, sore throat, } \\
\text { complete loss of smell }\end{array}$ \\
\hline 3 & $\begin{array}{l}\text { Less common } \\
\text { clinical signs }\end{array}$ & $\begin{array}{l}\text { Blue toes, reddish spots } \\
\text { on the skin }\end{array}$ \\
\hline 4 & $\begin{array}{l}\text { Respiratory phase } \\
\text { with prominent } \\
\text { signs of lower } \\
\text { respiratory tract } \\
\text { damage }\end{array}$ & $\begin{array}{l}\text { Dry cough, shortness of } \\
\text { breath, shortness of } \\
\text { breath }\end{array}$ \\
\hline 5 & $\begin{array}{l}\text { Gastrointestinal } \\
\text { tract damage }\end{array}$ & $\begin{array}{l}\text { Nausea, vomiting, } \\
\text { diarrhea }\end{array}$ \\
\hline
\end{tabular}

3.3. Development of a process chart of device for the determination of coronavirus antigens

The main focus in the field of health is given to scientific research for the manufacture of tests for a 
specific type of coronavirus [23-25]. Not enough attention is paid to the development of universal instruments for rapid analysis of the complex of coronaviruses.

After analyzing express technique for detecting coronavirus antigens, a process chart was made that includes six modules: module 1 - preparation of a biomaterial liquid medium $(X 0)$; module 2 - defining characteristic type of $\mathrm{CoV}$ for studied object and reel adjustment $(X H)$ (Reel can include up to 12 tests); module 3 - diagnostics of coronavirus antigens using special probe (The testing is based on a method based on the activity of cleavage of collateral single-stranded DNA (ssDNA) ; module 4 - technological break 5 min (at this moment, the antigen-antibody complex migrates and the test result signals are activated); module 5 - analysis of indicators and diagnosis of infection of studied biological medium with coronavirus (The activity of the test and control signals is analyzed and, based on the logical equation, a reaction to the presence of antibodies); module 6 - washing and disinfection of conveyor. Process chart of designed device for the determination of coronavirus antigens is shown in Fig. 2.

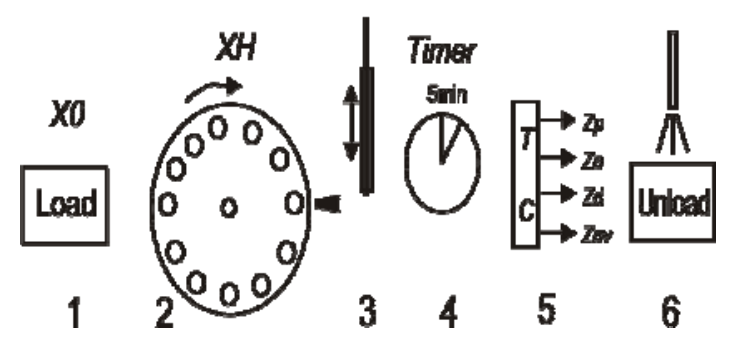

Fig. 2. Process chart of monitoring coronavirus antigens: 1 - loading of biomaterial; 2 - reel with installed sensors; 3 - probe drive; 4 - technological break; 5 - analysis unit; 6 - conveyor disinfection.

\subsection{Analysis and synthesis of control logic}

To implement the process chart of equipment operation and to build a model of an express analyzer, required logical elements were introduced that were structured by group and type of coronavirus (Table 2).

\subsubsection{Synthesis of a coronavirus antigen diagnostic device (module 5)}

Module 5 required for the diagnosis of coronavirus infection is the main module of this device. State and transition graph for analysis of coronavirus antigen is shown in Fig. 3.

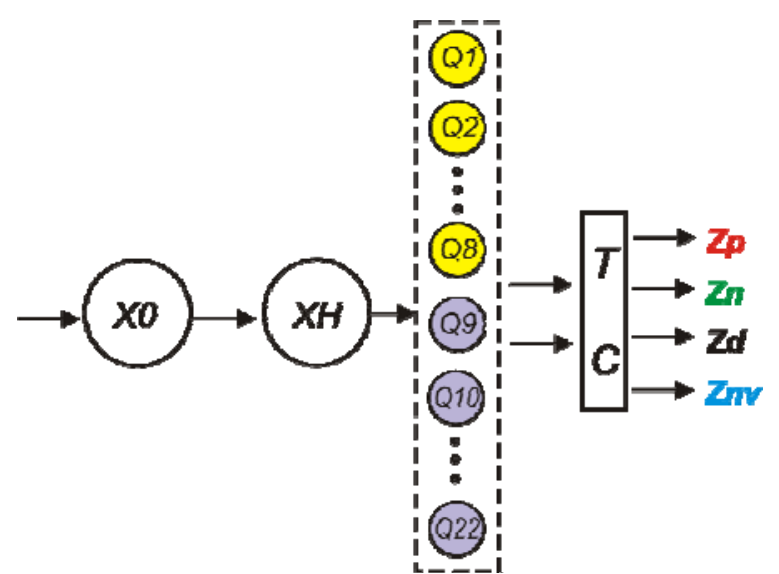

Fig. 3. State and transition graph for analysis of coronavirus antigen

At the first stage $(X 0)$, samples are taken. At the next stage, coronavirus antigen $(X H)$ typical for animal species or human is defined, and the reel with test samples is operated. Diagnostic results can show a positive or negative reaction, or can be equivocal or invalid based on the readings of detector signals. A set of diagnostic probes is proposed as indicator of $\mathrm{CoV}$ antibodies. The probe is a nitrocellulose membrane containing monoclonal antibodies that give test " $\mathrm{T}$ " and control "C" signals. Mobile $\mathrm{CoV}$ antibodies bind to colloidal gold particles deposited on conjugate pad, and secondary immobilized antibodies are applied to the " $\mathrm{T}$ " indicator zone. When a sufficient amount of coronavirus antigens enters the antibody zone, an antigen-antibody complex ( $\mathrm{mAb} / \mathrm{cG})$ migrates along the test membrane.

When a sufficient amount of coronavirus antigens enters the antibody zone, an antigen-antibody complex $(\mathrm{mAb} / \mathrm{cG})$ is formed that migrates along the test membrane. Having reached $\mathrm{T}$ line, $\mathrm{mAb} / \mathrm{cG}$ complex is captured by secondary immobilized antibodies with activation of " $T$ " signal. To control test validity, " $C$ " signal is used. Test for coronavirus antigen detection is performed in 5 minutes. Test result can be one of four values: negative $(Z n)$, positive $(Z p)$, equivocal $(Z d)$ and invalid $(Z n v)$. Relationship of $\mathrm{T}$ and $\mathrm{C}$ indicators and analysis results is given in the truth table (Table 3 ).

Table 3. Truth table for assay results.

\begin{tabular}{cccccc}
\hline \multicolumn{2}{c}{ Monitoring probes } & \multicolumn{4}{c}{ Assay results } \\
\hline $\mathrm{T}$ & $\mathrm{C}$ & $Z p$ & $Z n$ & $Z d$ & $Z n v$ \\
\hline 0 & 0 & 0 & 0 & 0 & 1 \\
0 & 1 & 0 & 1 & 0 & 0 \\
1 & 0 & 0 & 0 & 1 & 0 \\
1 & 1 & 1 & 0 & 0 & 0 \\
\hline
\end{tabular}


Table 2. Identification of logical elements.

\begin{tabular}{|c|c|c|c|c|c|}
\hline Variable & Name & Address & Note & Group & Object \\
\hline$X 0$ & PW & I: 0.00 & Sampling & & \\
\hline & & & Human, & & \\
\hline$X H$ & $\mathrm{GH}$ & 2.00 & GenomH & & \\
\hline$X A$ & GA & 3.00 & GenomA & & \\
\hline YlHa & Q1 & O: 100.01 & CoV-229E, & $\alpha$ & Human \\
\hline $\mathrm{Y2Ha}$ & Q2 & O: 100.02 & CoV-NL63 & $\alpha$ & Human \\
\hline $\mathrm{Y3Hb}$ & Q3 & O: 100.03 & CoV-HKU1 & $\beta$ & Human \\
\hline$Y 4 H b$ & Q4 & O: 100.04 & $\mathrm{CoV}-\mathrm{OC} 43$ & $\beta$ & Human \\
\hline $\mathrm{Y} 5 \mathrm{Hb}$ & Q5 & O: 100.05 & SARS-CoV & $\beta$ & Human \\
\hline Y6Hb & Q6 & O: 100.06 & MERS-CoV & $\beta$ & Human \\
\hline$Y 7 H b$ & Q7 & O: 100.07 & SARS-CoV-2 & $\beta$ & Human \\
\hline$Y 8 C g$ & Q8 & O: 100.08 & IBV & $\gamma$ & Chicken \\
\hline$Y 9 P$ & Q9 & O: 100.09 & PRCV/ISU-1 & $\alpha$ & Pig \\
\hline$Y 10 P$ & Q10 & O: 100.10 & $\begin{array}{l}\text { TGEV/ } \\
\text { PUR46-MAD }\end{array}$ & $\alpha$ & Pig \\
\hline$Y 11 P$ & Q11 & O: 100.11 & $\begin{array}{l}\text { PEDV/ZJU- } \\
\text { G1-2013 }\end{array}$ & $\alpha$ & Pig \\
\hline$Y 12 P$ & Q12 & O: 100.12 & $\begin{array}{l}\mathrm{SeACoV}-\mathrm{CH} \\
\text { /GD-01 }\end{array}$ & $\alpha$ & Pig \\
\hline$Y 13 C g$ & Q13 & O: 100.13 & $\begin{array}{l}\mathrm{CoV} / \mathrm{TU} 336 / \\
\mathrm{F} / 2008\end{array}$ & $\alpha$ & Dog \\
\hline$Y 14 C g$ & Q14 & O: 100.14 & Isolate camel/Riyadh & $\alpha$ & Camel \\
\hline$Y 15 C g$ & Q15 & O: 100.15 & $\begin{array}{l}\text { Feline infectious } \\
\text { peritonitis }\end{array}$ & $\alpha$ & Cat \\
\hline$Y 20 C g$ & Q20 & O: 100.20 & Bovine CoV/ENT & $\gamma$ & Cow \\
\hline Y21Hsg & Q21 & O: 100.21 & $\begin{array}{l}\mathrm{CoV} / \\
\text { Obihiro12-1 }\end{array}$ & $\gamma$ & Horse \\
\hline$Y 22 B d$ & Q22 & O: 100.22 & HKU11 & $\delta$ & Bulbul \\
\hline
\end{tabular}




\section{Synthesis of combinational logic}

Synthesis of logical equations to obtain the minimum disjunctive normal form (MDNF) was based on Karnaugh map (Table 4-7) [26, 27].

Table 4. Karnaugh map Table 5. Karnaugh map

\begin{tabular}{|c|c|c|c|c|c|}
\hline \multicolumn{3}{|c|}{$(Z p)$} & \multicolumn{3}{|c|}{$(Z n)$} \\
\hline $\mathrm{T}$ & 0 & 1 & & 0 & 1 \\
\hline 0 & 0 & 0 & 0 & 0 & 0 \\
\hline 1 & 0 & 1 & 1 & 1 & 0 \\
\hline & & & & & \\
\hline
\end{tabular}

Table 6. Karnaugh Table 7. Karnaugh map

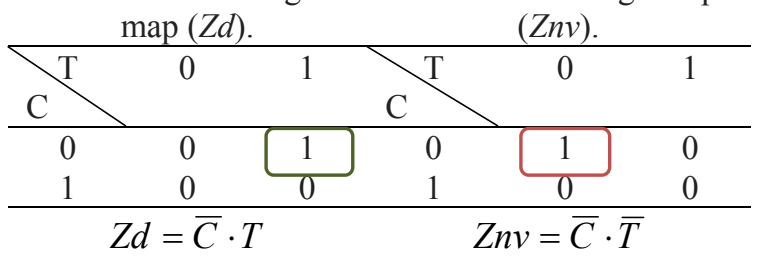

Fig. 4 shows a ladder diagram for determining coronavirus antigen constructed with the use of obtained logical expressions.

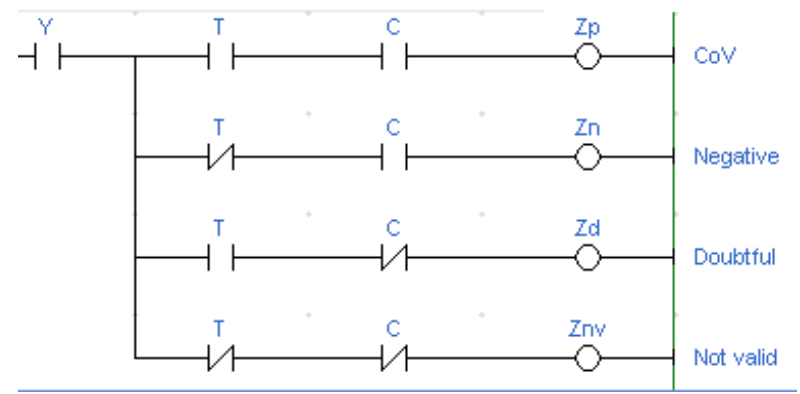

Fig. 4. Fragment of the relay logic for indicating the search for coronavirus antigen, " $\mathrm{T}$ " is a test indicator of antigen, " $\mathrm{C}$ " is a measurement verification

\subsubsection{Synthesis of a container control device (module 1)}

Container is designed to load biomaterial for research. The task of container control drive is to deliver biomaterial to diagnostic module. Container has two stable positions, open and closed, fixed by sensors. State and transition graph of container drive control is shown in Fig. 5.

Logical equation for container drive control can be written as following:

$$
\left\{\begin{array}{l}
\text { Yon }=(\text { LD } \vee \text { Yon }) \cdot \text { Open } \cdot \overline{\text { Close }} \\
\text { Yoff }=(U n L D \vee Y o f f) \cdot \overline{\text { Open }} \cdot \text { Close }
\end{array}\right.
$$

Developed ladder diagram for container drive control is shown in Fig. 6.

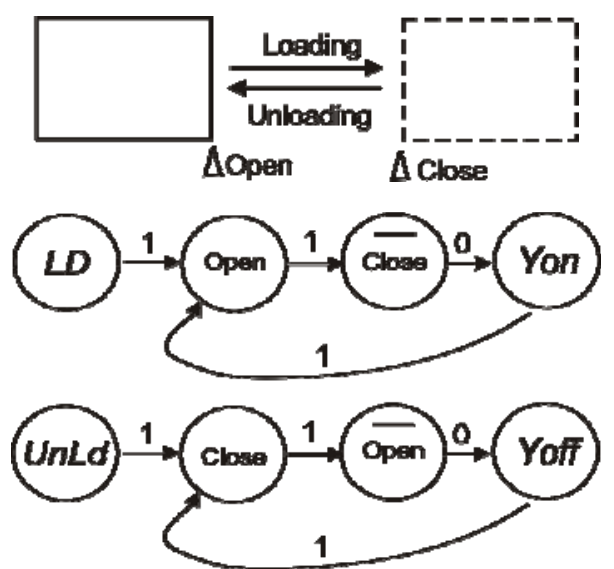

Fig. 5. State and transition graph of container drive control: $L D / U n L d$ - loading/unloading, Open, Close container position sensors, Yon/Yoff - drive.

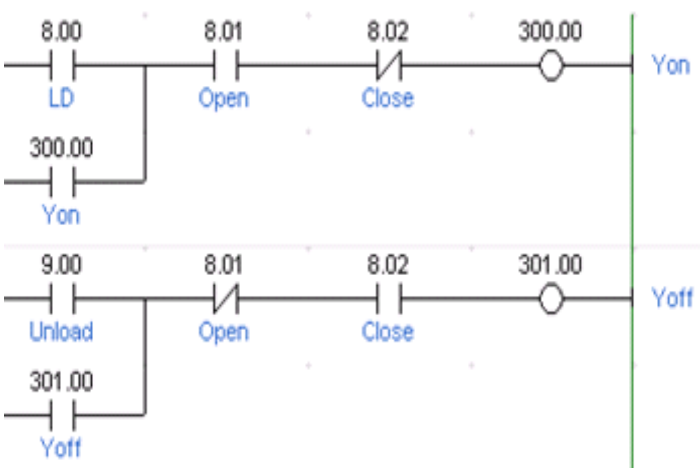

Fig. 6. Ladder diagram for container drive control

\subsubsection{Synthesis of reel control device (module 2)}

A reel is a mechanism that carries diagnostic material; reel drive control means setting it in a specific position for the diagnosis of probable coronavirus antigen. State and transition graph for reel drive control is shown in Fig. 7.

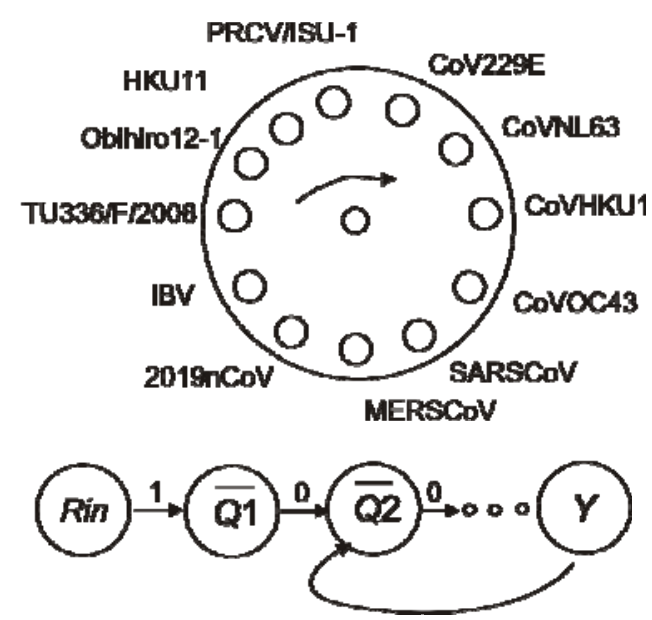

Fig. 7. State and transition graph for reel drive control: Rin - reel start, $Q x$ - reel position sensors, $Y$ - reel drive 

form:

Logical equation for reel drive will take the following $Y=(\operatorname{Rin} \vee Y) \cdot \overline{Q 1} \cdot \overline{Q^{2}} \cdot \overline{Q^{3}} \cdot \overline{Q 4} \cdot \overline{Q 5} \cdot \overline{Q 6} \cdot \overline{Q 7} \cdot \ldots \cdot \overline{Q^{22}}$.

A fragment of ladder diagram is shown in Fig. 8.

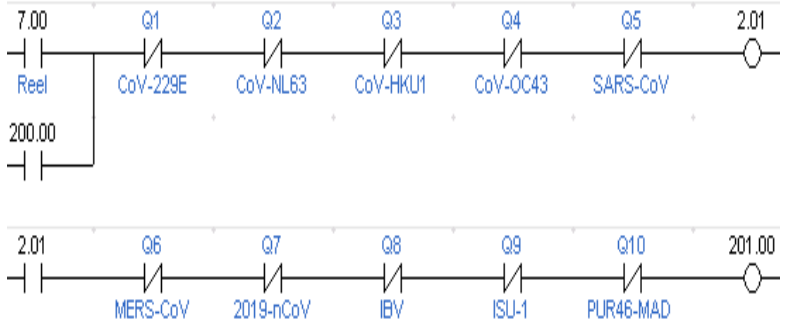

Fig. 8. Fragment of ladder diagram of reel control

\subsubsection{Synthesis of a probe control device (module 3)}

Normal position of diagnostic probe is the top one; for testing, the probe drops into studied biomass and returns to initial position. State and transition graph of probe control is shown in Fig. 9.

System of logical equations for probe control will look like:

$$
\left\{\begin{array}{l}
\text { Yts }=(\text { Test } \vee \text { Yts }) \cdot \text { Top } \cdot \overline{\text { Bootom }} \\
\text { Ytsoff }=(\text { Testoff } \vee \text { Ytsoff }) \cdot \text { Bootom } \cdot \overline{\text { Top }}
\end{array}\right.
$$

Developed ladder diagram is shown in Fig. 10.

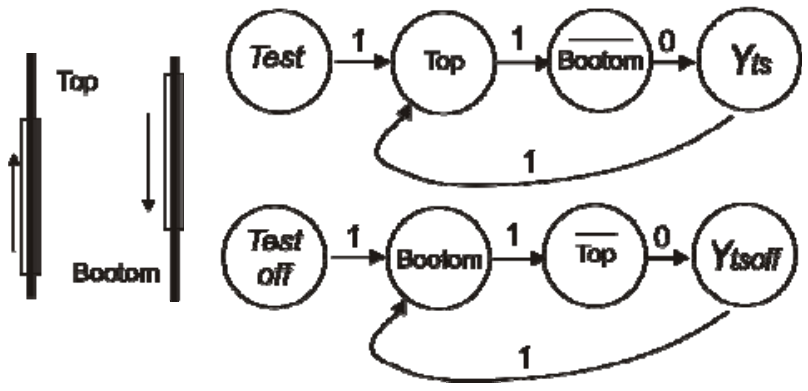

Fig. 9. State and transition graph of diagnostic probe control

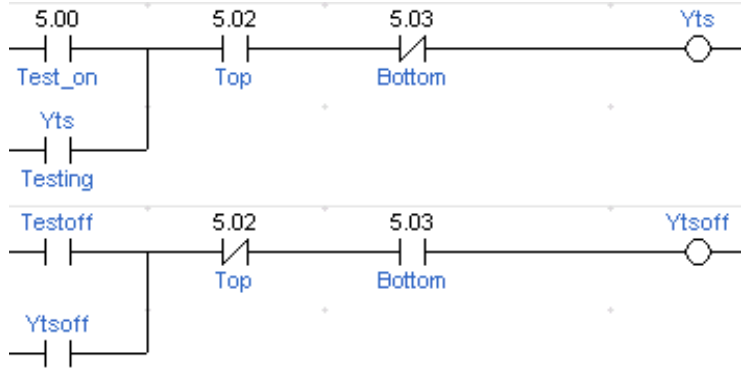

Fig. 10. Fragment of ladder diagram of probe control
3.4.5. Designing a technological break module (module 4)

Technological break is associated with the time interval required for the distribution of the concentration of $c(x, t)$ antigen-antibody $(\mathrm{mAb} / \mathrm{cG})$ complex along the test membrane and activation of " $\mathrm{T}$ " and " $\mathrm{C}$ " signals.

A flow $q(x, t)$ is understood as the amount of substance $\mathrm{n}_{\mathrm{mAb} / \mathrm{cG}}$ passing through a certain mark $\xi$ of test membrane (Fig. 11).

$$
q(x, t)=\left.\lim _{\Delta t \rightarrow 0} \frac{\Delta n}{\Delta t}\right|_{\xi}=\frac{\partial n}{\partial t} .
$$

Upon reaching concentration

$$
c(\xi, \tau)_{\mathrm{mAb} / \mathrm{cG}}>c(\xi, \tau)_{\min },
$$

test signals are activated.

General equation for the maintenance of material mass of $\mathrm{mAb} / \mathrm{cG}$ complex can be written as Euler equation

$$
\frac{\partial c(x, t)}{\partial t}+\frac{\partial q(x, t)}{\partial x}=0
$$

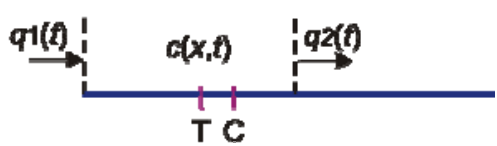

Fig. 11. Scheme of migration of antigen-antibody complex $(\mathrm{mAb} / \mathrm{cG})$ along the test membrane

Timer control graph is shown in Fig. 12.

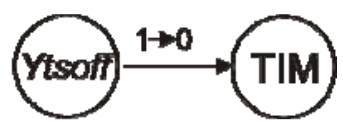

Fig. 12. State graph for timer control (TIM)

Ladder diagram of the organization of technological break is shown in Fig. 13.

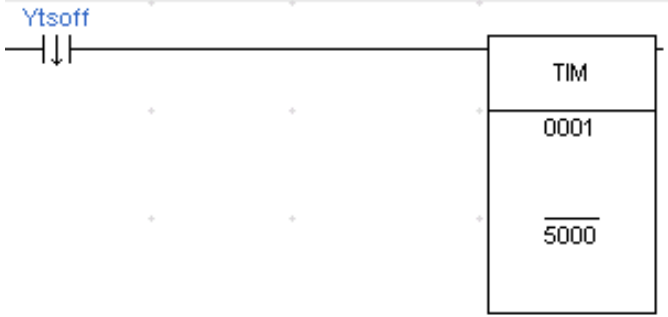

Fig. 13. Ladder diagram for timer control (TIM)

3.4.6. Synthesis of a fluid nozzle control device (module 6)

After the assay, it is necessary to rinse and disinfect the tray, for this a nozzle control mechanism is provided. Nozzle control graph is shown in Fig. 14.

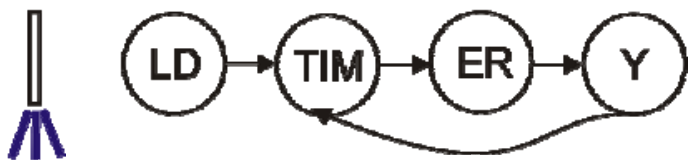

Fig. 14. State graph for nozzle control: TIM - timer, ER - device error 
Logical equation for nozzle control is written in the form of:

$$
\left\{\begin{array}{l}
\text { Disp }=(\text { Fix } \vee \text { Disp }) \cdot \overline{\text { Timer }} \cdot \text { No } \_ \text {sol } \\
\text { Timer }=\text { Disp }
\end{array}\right.
$$

Developed ladder diagram is shown in Fig. 15.

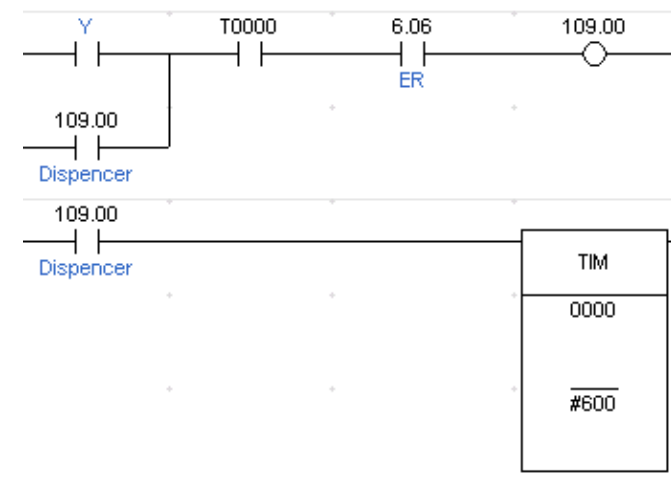

Fig. 15. Ladder diagram for nozzle control to wash the container

3.4.7. Developing the general system of logical equations for device control

Thus, the main elements of device operation can be described by the following system of equations:

$$
\begin{aligned}
& \text { Start }=(\text { Start_On } \vee \text { Start }) \cdot \overline{\text { Stop }} \\
& \{\text { Yon }=(L D \vee Y o n) \cdot \text { Open } \cdot \overline{\text { Close }} \\
& \text { Yoff }=(U n L D \vee Y o f f) \cdot \overline{\text { Open }} \cdot \text { Close } \\
& Y=(\operatorname{Rin} \vee Y) \cdot \overline{Q 1} \cdot \overline{Q 2} \cdot \overline{Q 3} \cdot \overline{Q 4} \cdot \overline{Q 5} \cdot \overline{Q 6} \cdot \overline{Q 7} \cdot \ldots \cdot \overline{Q 22} \text {. } \\
& \left\{\begin{array}{l}
\text { Yts }=(\text { Test } \vee \text { Yts }) \cdot \text { Top } \cdot \overline{\text { Bootom }} \\
\text { Ytsoff }=(\text { Testoff } \vee \text { Ytsoff }) \cdot \text { Bootom } \cdot \overline{\text { Top }}
\end{array}\right. \\
& \text { Timer }=\overline{\text { Ytsoff }} \downarrow \\
& \mathrm{Zp}=\mathrm{C} \cdot \mathrm{T} \\
& \mathrm{Zn}=\mathrm{C} \cdot \bar{T} \\
& Z d=\bar{C} \cdot T \\
& Z n v=\bar{C} \cdot \bar{T} \\
& \left\{\text { Disp }=(\text { Fix } \vee \text { Disp }) \cdot \overline{\text { Timer }} \cdot N_{-}\right. \text {sol } \\
& \text { Timer }=\text { Disp } \\
& \left\{\begin{array}{l}
\text { Yon }=(\text { LD } \vee \text { Yon }) \cdot \text { Open } \cdot \overline{\text { Close }} \\
\text { Yoff }=(U n L D \vee \text { Yoff }) \cdot \overline{\text { Open }} \cdot \text { Close }
\end{array}\right.
\end{aligned}
$$

Ladder diagram of device operation is shown in Fig. 16 and Fig. 17.

\subsubsection{Simulation of express analysis system}

Simulation of express analysis system is necessary for verifying the correct operation of device modules. To make a model of an express analyzer, we selected Omron PLC which was proven to work well for medical and veterinary purposes [28, 29]. Development of ladder diagram (LD) of the device was carried out using CX-Programmer. Development of touch monitor for a laboratory assistant of express analysis operator was performed using CX-Designer module. Developed interface of express analysis device is shown in Fig. 18. Operation of express analysis diagnostic scheme as illustrated by detection of 2019-nCoV coronavirus antigen for different states of test signals is shown in Fig. 19-22.

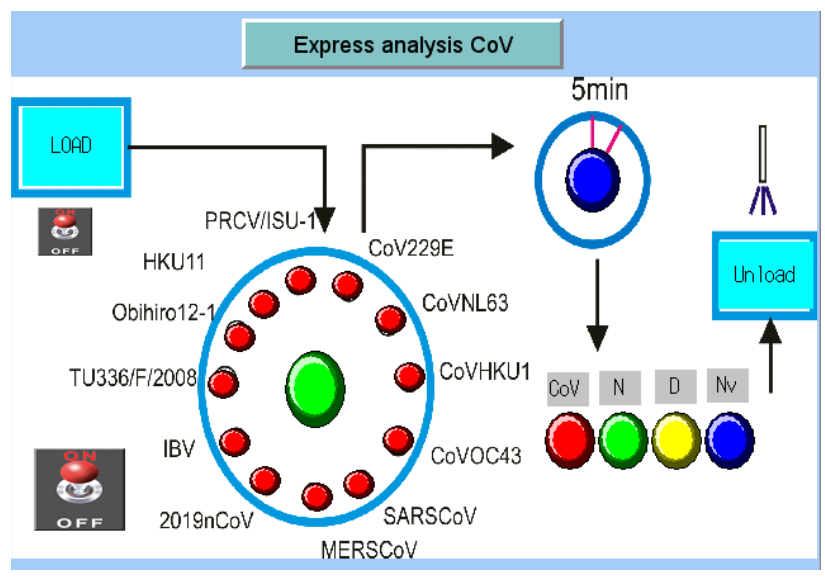

Fig. 18. Structure of dialog box of express analysis diagnostic system

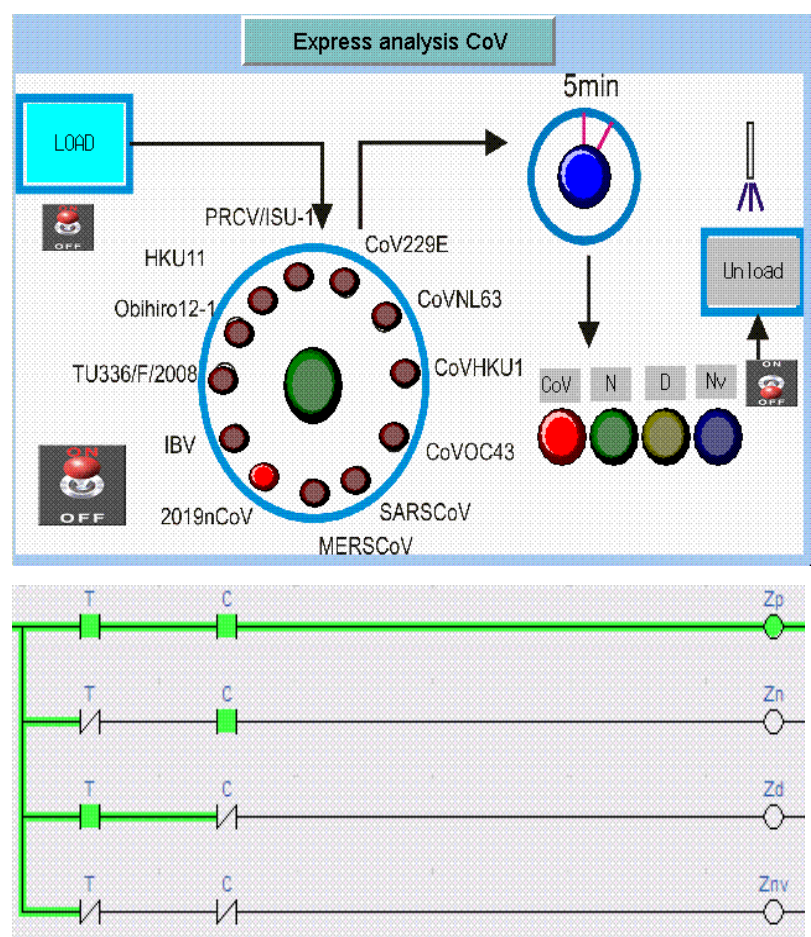

Fig. 19. Ladder diagram shows activated " $T$ " and " $C$ " signals, positive result for CoV (Zp). Signals for 2019$\mathrm{nCoV}$ and $\mathrm{CoV}$ are activated in analyzer dialog box

(coronavirus 2019-nCoV antigen was found) 


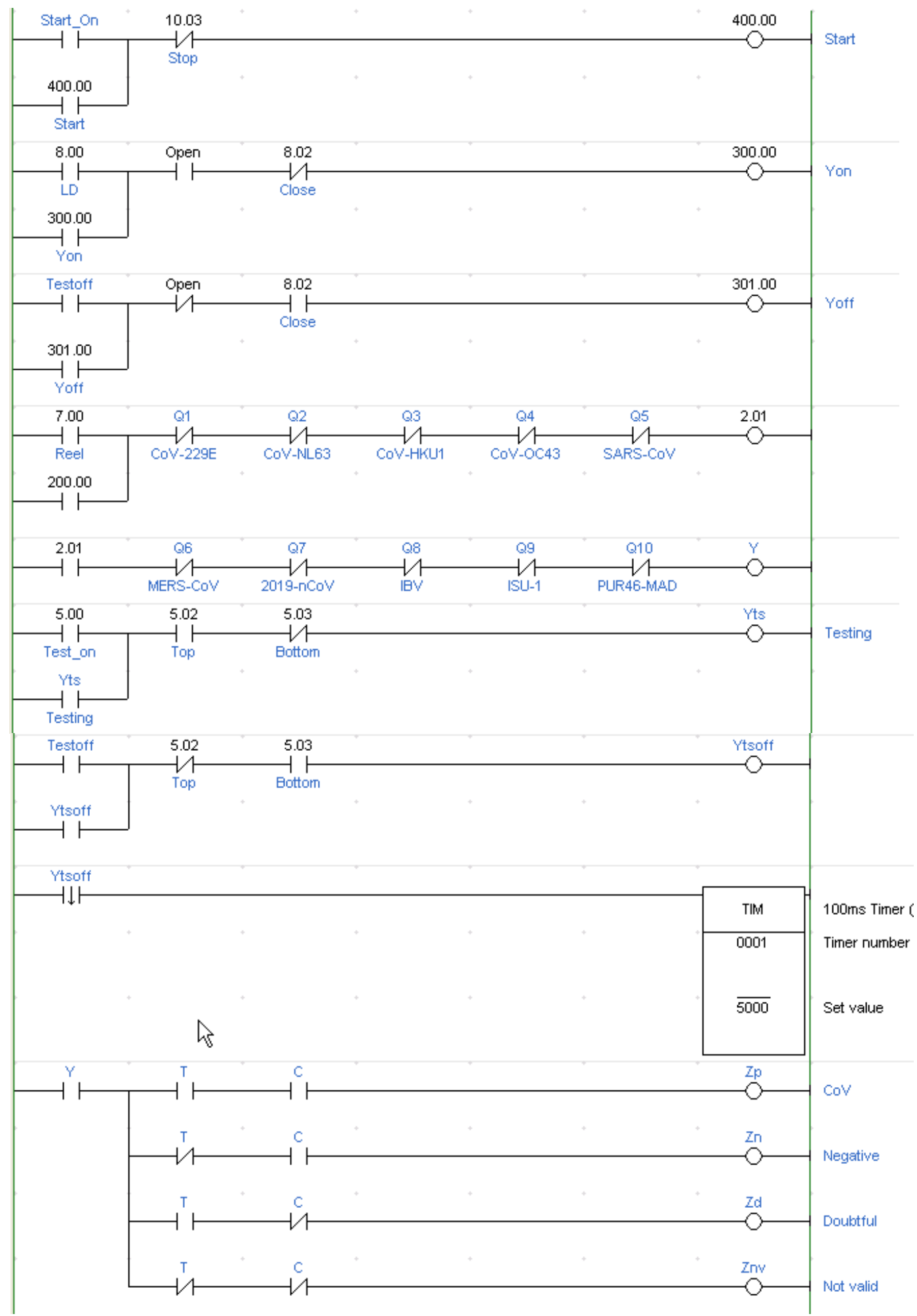

Fig. 16. Ladder diagram of device control (modules 1-5) 


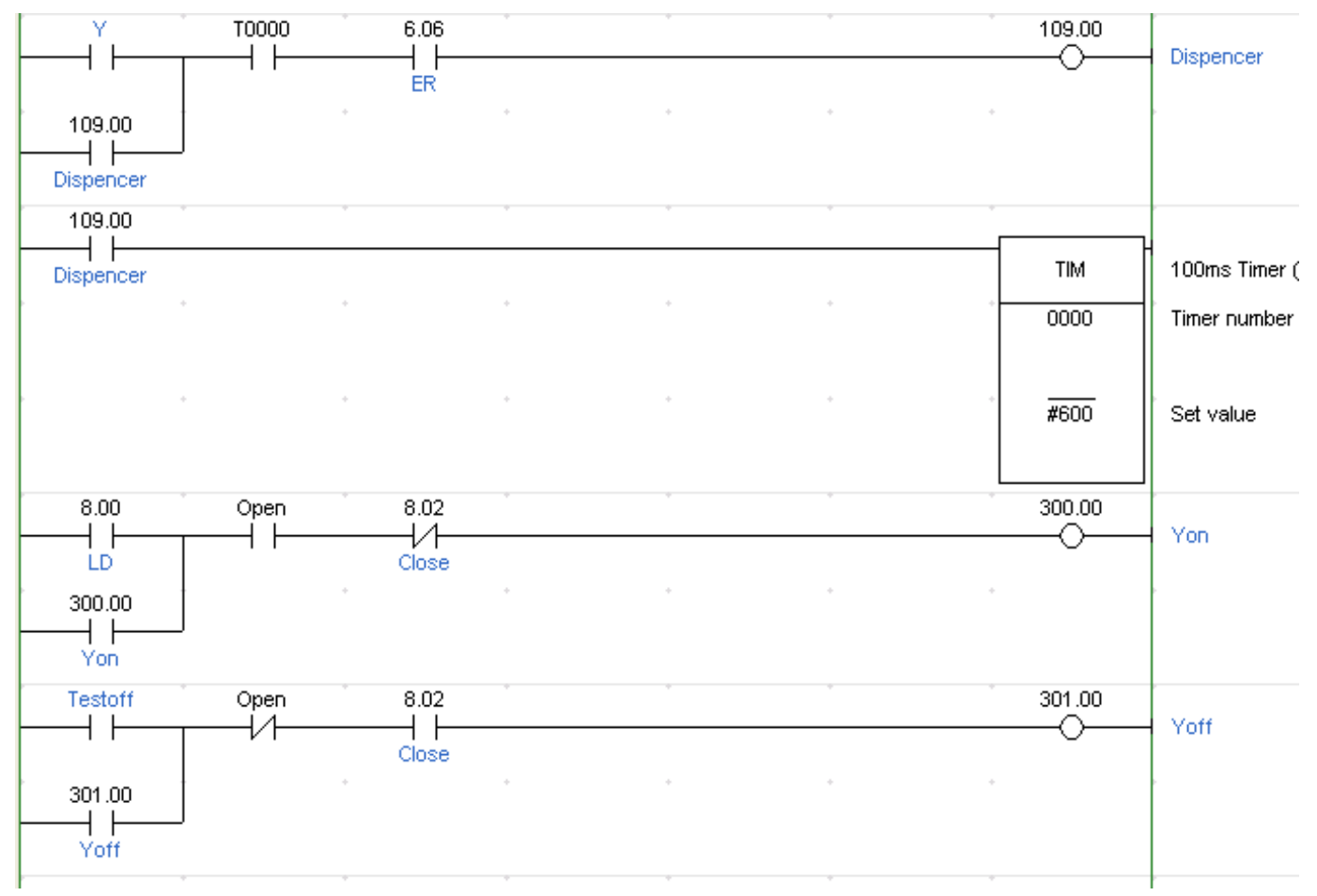

Fig. 17. Ladder diagram of device control (module 6)

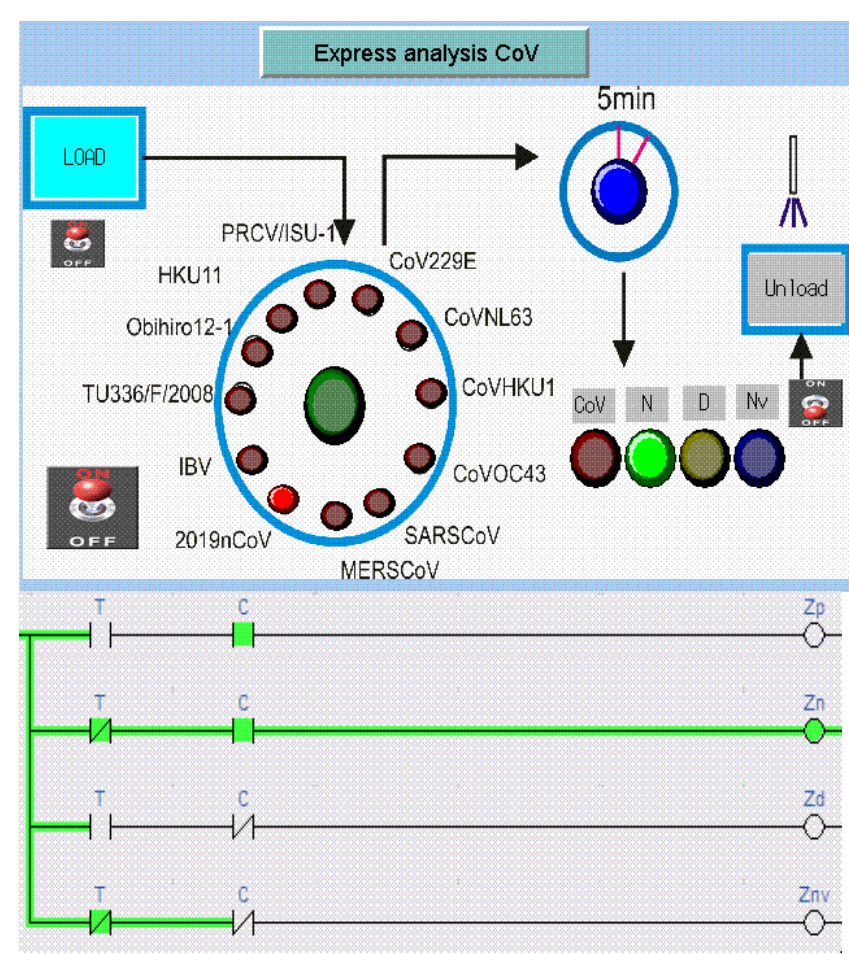

Fig. 20. C signal is activated on LD, negative result for $\mathrm{CoV}(\mathrm{Zn}) . \mathrm{N}$ (negative) signal is activated in analyzer dialog box

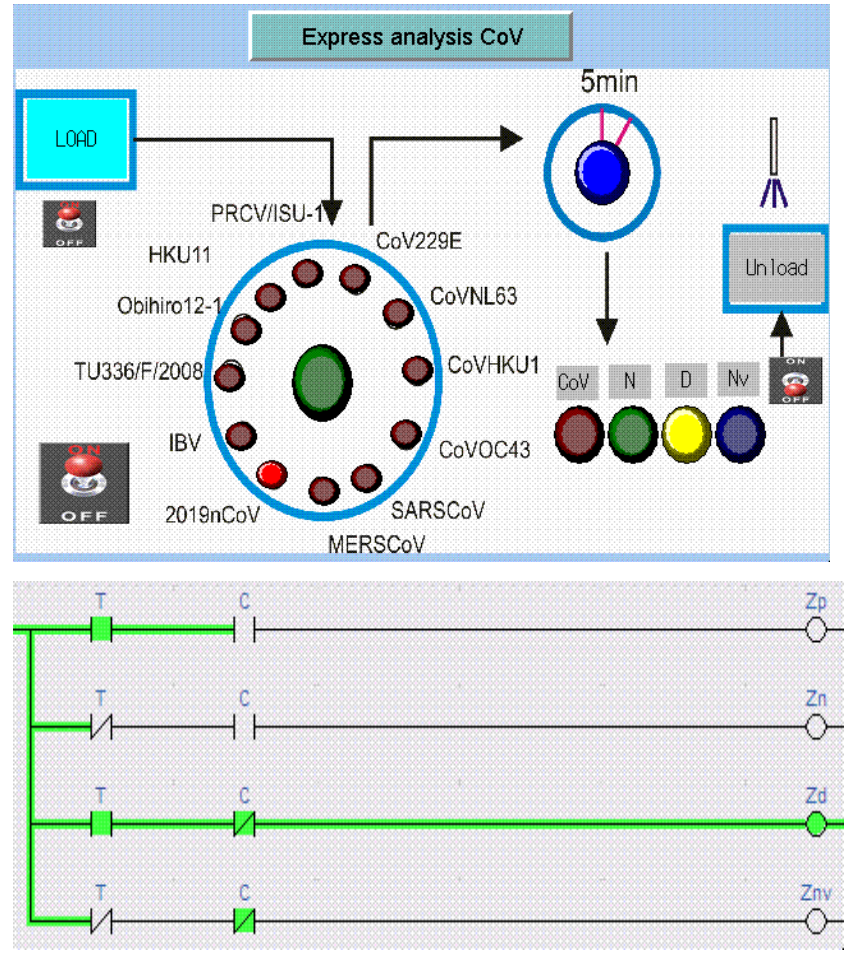

Fig. 21. "T" signal was activated on LD but test validity "C" was not confirmed; the result is equivocal $(\mathrm{Zd})$. D (negative) signal is activated in analyzer dialog box 


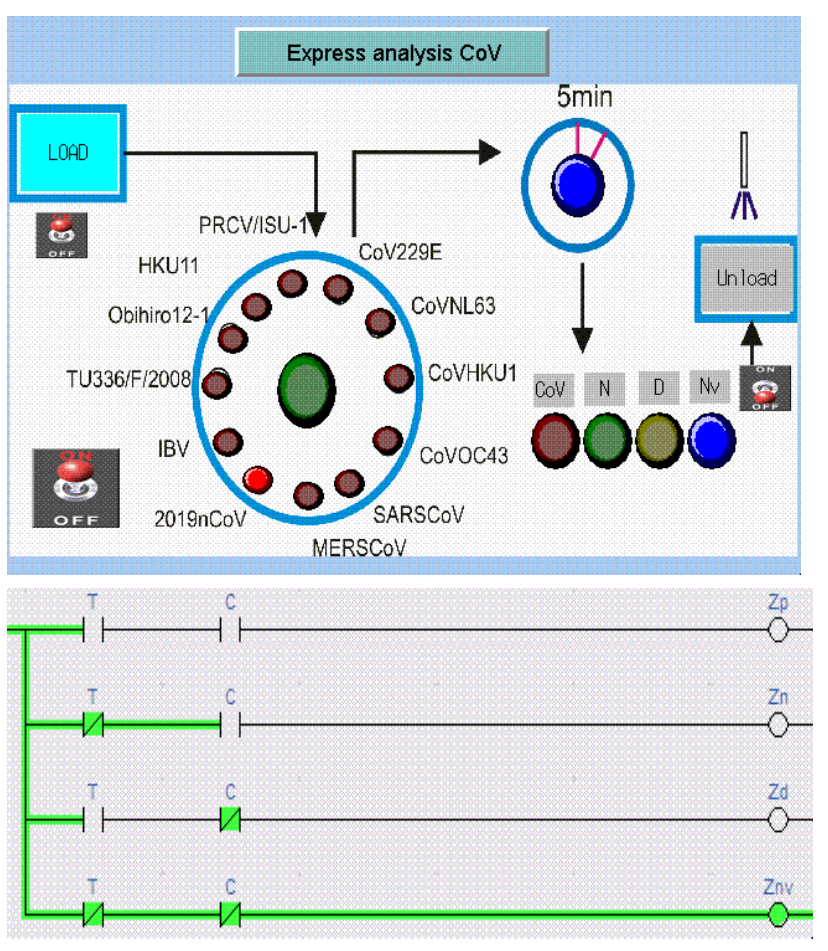

Fig. 22. LD shows inactive "T" and "C" signals (Znv). Nv (not valid) indicator is turned on in analyzer dialog box. The result is invalid

Simulation of the express analysis program showed the correct logic of test system and signal indicators on designed device panel.

\section{CONCLUSION}

This article describes the issues of determining the primary symptoms of human and animal diseases when infected with coronavirus. To accelerate diagnosing and to increase the safety of medical and veterinary staff, we proposed a developed project of an express analysis device for defining coronavirus infection. Technique of express analysis of Coronaviridae infection was studied with the help of special diagnostic probes based on the use of secondary immobilized antibodies. Process chart of the designed device was developed. Logical equations and ladder diagrams were developed and implemented in OMRON hardware-software complex. Development of a device for rapid diagnosis of coronavirus infection will solve the problem of safety and efficiency and reduce the epidemiological situation associated with coronavirus spreading in the world, due to the fact that people will be able to quickly make a diagnosis, and promptly apply measures for self-isolation and treatment.

New test systems based on microfluidic chips and a 96-well plate with optical recording of results are currently being developed.

\section{References}

[1] X. Tian, C. Li, A. Huang, S. Xia, S. Lu, Z. Shi, L. Lu, S. Jiang, Z. Yang, Y. Wu, T. Ying, "Potent binding of 2019 novel coronavirus spike protein by a SARS coronavirusspecific human monoclonal antibody," Emerging microbes \& infections, Vol. 9, no. 1, pp. 382-385, 2020.

[2] W. Zhang, R.-H. Du, B. Li, X.-S. Zheng, X.-L. Yang, B. $\mathrm{Hu}$, Y.-Y. Wang, G.-F. Xiao, B. Yan, Z.-L. Shi, P. Zhou,"Molecular and serological investigation of 2019nCoV infected patients: implication of multiple shedding routes," Emerging microbes \& infections, Vol. 9, no. 1, pp. 386-389, 2020.

[3] C. Xiao, X. Li, S. Liu, Y. Sang, S.-J. Gao, et al., "HIV-1 did not contribute to the 2019-nCoV genome," Emerging microbes \& infections, Vol. 9, no. 1, pp. 378-381, 2020.

[4] J. F.-W. Chan, K.-H. Kok, Z. Zhu, H. Chu, K. K.-W. To, S. Yuan, K.-Y. Yuen, "Genomic characterization of the 2019 novel human-pathogenic coronavirus isolated from a patient with atypical pneumonia after visiting Wuhan," Emerging microbes \& infections, Vol. 9, no. 1, pp. 221-236, 2020.

[5] Z. Song, Y. Xu, L. Bao, L. Zhang, P. Yu, Y. Qu, H. Zhu, W. Zhao, Y. Han, C. Qin,"From SARS to MERS, thrusting coronaviruses into the spotlight," Viruses, Vol. 11 , no. 1, p. 59, 2020.

[6] S. Takyu, A. M. Ahmed, E. Yoshida, H. Tashima, M. Kumagai, T. Yamashita, T. Yamaya, "Design study of a brain-dedicated time-of-flight PET system with a hemispherical detector arrangement," Physics in medicine and biology, Vol. 65, no. 3, p. 035012, 2020.

[7] Y. Han, H. Yang,"The transmission and diagnosis of 2019 novel coronavirus infection disease (COVID-19): A Chinese perspective", Journal of Medical Virology, Vol. 92 (6), pp. 639-644, 2020.

[8] T. P. Sheahan, A. C. Sims, S. R. Leist, A. Schäfer, J. Won, A.J. Brown, S.A. Montgomery, A. Hogg, D. Babus, M.O. Clarke, J.E. Spahn, L. Bauer, Sellers, D. Porter, J.Y. Feng, S.T. Cihlar, R. Jordan, M.R. Denison, R.S. Baric, "Comparative therapeutic efficacy of remdesivir and combination lopinavir, ritonavir, and interferon beta against MERS-CoV," Nature Communications, Vol. 11 no. 1, p. 222, 2020.

[9] Y. Cao, L. Li, Z. Feng, S.Wan, P. Huang, X. Sun, F. Wen, X. Huang, G. Ning, W. Wang, "Comparative genetic analysis of the novel coronavirus (2019nCoV/SARS-CoV-2) receptor ACE2 in different populations," Cell Discovery, Vol. 6, no. 1, p. 11, 2020.

[10] W.-C. Chao, C.-H. Tseng, C.-L. Wu, S.-J. Shih, C.-Y. Yi, M.-C. Chan, "Higher glycemic variability within the first day of ICU admission is associated with increased 30-day mortality in ICU patients with sepsis," Annals of Intensive Care, Vol. 10, no. 1, p. 17, 2020.

[11] Y. Jin, M. Wang, Z. Zuo, C. Fan, F. Ye, Z. Cai, Y. Wang, H. Cui, K. Pan, A. Xu, "Diagnostic value and dynamic variance of serum antibody in coronavirus 
disease 2019", International Journal of Infectious Diseases, Vol.94, pp. 49-52, 2020.

[12] M.R.O. Chisale, D. Salema, F. Sinyiza, J. Mkwaila, P. Kamudumuli, H.-Y. Lee, "A comparative evaluation of three methods for the rapid diagnosis of cryptococcal meningitis $(\mathrm{Cm})$ among hiv-infected patients in northern Malawi”, Malawi Medical Journal, Vol. 32(1), pp. 3-7, 2020.

[13] T.-M. Chen, J. Rui, Q.-P. Wang, Z.-Y. Zhao, J.-A. Cui, L. Yin, "A mathematical model for simulating the phasebased transmissibility of a novel coronavirus", Infectious Diseases of Poverty, vol. 9(1), p. 24, 2020.

[14] K. Wu, D. Darcet, Q. Wang and D. Sornette, "Generalized logistic growth modeling of the COVID-19 outbreak in 29 provinces in China and in the rest of the world", https://arxiv.org/ftp/arxiv/papers/2003/ 2003.05681.pdf.

[15] J. Park, S.Y. Yoo, J.-H. Ko, S.M. Lee, Y.J. Chung, J.-H. Lee, K.R. Peck, J.J. Min, "Infection Prevention Measures for Surgical Procedures during a Middle East Respiratory Syndrome Outbreak in a Tertiary Care Hospital in South Korea," Scientific Reports, Vol. 10, no. 1, p. 325, 2020.

[16] H. Wang, Z. Wang, Y. Dong, R. Chang, C. Xu, X. Yu, S. Zhang, L. Tsamlag, M. Shang, J. Huang, Y. Wang, G. $\mathrm{Xu}, \mathrm{T}$. Shen, X. Zhang, Y. Cai, "Phase-adjusted estimation of the number of Coronavirus Disease 2019 cases in Wuhan, China," Cell Discovery, Vol. 6, no. 1, p. $10,2020$.

[17] T. Phan, "Genetic diversity and evolution of SARSCoV-2," Infection, Genetics and Evolution, Vol. 81, p. 104260, 2020.

[18] N.H. Zaher, M.I. Mostafa, A.Y. Altaher, "Design, synthesis and molecular docking of novel triazole derivatives as potential $\mathrm{CoV}$ helicase inhibitors," Acta Pharmaceutica, Vol. 70, no. 2, pp. 145-159, 2020.

[19] A.M. Marty, M.K. Jones, "The novel Coronavirus (SARS-CoV-2) is a one health issue," One Health, Vol. 9, p. 100123, 2020.

[20] P. Aich, H.L. Wilson, R.S. Kaushik, A.A. Potter, L.A. Babiuk, P. Griebel, "Comparative analysis of innate immune responses following infection of newborn calves with bovine rotavirus and bovine coronavirus," J. Gen. Virol, Vol. 88, pp. 2749-2761, 2007.

[21] R.E. Holland, "Some infectious causes of diarrhea in young farm animals," Clinical Microbiological Reviews, Vol. 3, pp. 345-375,1990.

[22] H.-W. Chang, R.J. de Groot, H.F. Egberink, "Feline Infectious Peritonitis: insights into feline coronavirus pathobiogenesis and epidemiology based on genetic analysis of the viral 3c gene," Journal of General Virology, Vol. 91, no. 415, p. 420, 2010.

[23] F. Ucar, D. Korkmaz, "COVIDiagnosis-Net: Deep Bayes-SqueezeNet based diagnosis of the coronavirus disease 2019 (COVID-19) from X-ray images" Medical Hypotheses, 140, p. 109761, 2020.

[24] W. Schweitzer, T. Ruder, R. Baumeister, S. Bolliger, M. Thali, E. Meixner, G. Ampanozi, "Implications for forensic death investigations from first Swiss post- mortem CT in a case of non-hospital treatment with COVID-19”, Forensic Imaging, vol. 21,p. 200378, 2020.

[25] T.-T. Zhou, F.-X. Wei, "Primary stratification and identification of suspected Corona virus disease 2019 (COVID-19) from clinical perspective by a simple scoring proposal", Military Medical Research, vol. 7(1), p. 16, 2020.

[26] T.G. Sereda, N.A. Tatarnikova, "Development of an automated system histology security of food production," IOP Conference Series: Earth and Environmental Science, Vol. 315, no. 3, p. 032003, 2019.

[27] S.N. Kostarev, T.G. Sereda, N.A. Tatarnikova, O.V. Kochetova, "Creation of the automatic machine of the cell pathology recognizer," IOP Conference Series: Earth and Environmental Science, Vol. 421, p. 042003, 2020.

[28] T.G. Sereda, S.N. Kostarev, "Development of automated control system for waste sorting," IOP Conference Series: Materials Science and Engineering, Vol. 537, no.6, p. 062012, 2019.

[29] S.N. Kostarev, T.G. Sereda, "Microclimate Control System Development," IOP Conference Series: Materials Science and Engineering, Vol. 450, no. 6, p. 062013, 2018.

\section{Creative Commons Attribution License 4.0 (Attribution 4.0 International, CC BY 4.0)}

This article is published under the terms of the Creative Commons Attribution License 4.0 https://creativecommons.org/licenses/by/4.0/deed.en_US 